\title{
Radar mapping of Isunnguata Sermia, Greenland
}

\author{
K. JEZEK, ${ }^{1}$ X. WU, ${ }^{2}$ J. PADEN, ${ }^{3}$ C. LEUSCHEN ${ }^{3}$ \\ ${ }^{1}$ Byrd Polar Research Center, The Ohio State University, Columbus, OH, USA \\ E-mail: jezek.1@osu.edu \\ ${ }^{2}$ Jet Propulsion Laboratory, California Institute of Technology, Pasadena, CA, USA \\ ${ }^{3}$ Center for Remote Sensing of Ice Sheets, University of Kansas, Lawrence, KS, USA
}

\begin{abstract}
Ice thickness estimates using advanced nadir sounding and tomographic radar processing techniques are compared and combined in a study of Isunnguata Sermia glacier, Greenland. Using an ensemble of Operation IceBridge flight lines spaced at $500 \mathrm{~m}$ intervals and running approximately along the flow direction, we find there is a statistically excellent comparison between subglacial terrains derived from two-dimensional tomography and gridded nadir sounding. Analysis shows that tomographic data better capture short wavelength $(1-2 \mathrm{~km})$ patterns in basal terrain, but interpolated nadir sounding data yield more spatially extensive and continuous coverage across the glacier, especially in deep subglacial troughs. Using derived surface and basal topography maps, we find that driving stress and measured and modeled surface velocity comparisons indicate that basal sliding is an important component of the glacier motion, but is also only weakly coupled to the detailed bed topography save for the deepest troughs. As might be expected for this land-terminating, relatively slow-moving glacier, the subglacial and proglacial topography is similar, suggesting the erosional processes acting on the modern glacier bed once helped sculpt the now exposed land.
\end{abstract}

\section{INTRODUCTION}

There are fundamental glaciological measures necessary to understand the current status and to predict the future behavior of Earth's ice sheets. These measures are surface velocity field, surface accumulation rate field, surface topography, basal topography (or ice thickness) and internal temperature. Together they form the basis for estimating glacier mass balance and dynamics through the mass continuity and force-balance equations.

Of these, the surface velocity field is well measured with synthetic aperture radar (SAR) interferometry (Jezek, 2003, 2008; Joughin and others, 2010; Rignot and others, 2011). Surface topography is captured in great detail with airborne (Hofton and others, 2008) and satellite altimeters (Schutz and others, 2005) as well as from stereo-photogrammetry, which again can be acquired from spacecraft or aircraft (Howat and others, 2008). Surface accumulation rate is more difficult to measure remotely with high spatial and temporal accuracy (Munk and others, 2003; Arthern and others, 2006), but modeling work is closing that gap in our knowledge (Ettema and others, 2009). Temperature data at depth remain an elusive goal using any technique other than direct measurements in boreholes. Remaining in the list is basal topography, or alternatively ice thickness, which is the subject of this paper.

Ice thickness measurements have been carried out in situ on glaciers and ice sheets using gravity (Bull and Hardy, 1956), radar (Waite and Schmidt, 1962; Waite, 1966; Bogorodsky and others, 1985) and seismic techniques (Sorge, 1933; Peters and others, 2008). Both radar and gravity measurements (Peters and others, 2007; Diehl and others, 2008; Humbert and Steinhage, 2011) have been completed routinely across large portions of ice sheets using airborne instruments and also as part of NASA's Operation IceBridge (OIB) program (Koenig and others, 2010). In particular, technologically sophisticated radar systems developed by the University of Kansas (Gogineni and others, 1998, 2001; Rodriguez-Morales and others, in press) have been mounted in IceBridge aircraft and these instruments have successfully sounded extensive sectors of the Greenland and Antarctic ice sheets (http://www.nasa.gov/mission_pages/icebridge/).

Up until recently, these instruments have been operated optimally as nadir depth sounders, which is a desirable configuration for minimizing off-nadir clutter signals and increasing the sensitivity to weak basal returns. In 2003, a project was begun to investigate the potential for swath mapping of the ice-sheet base. Several approaches were identified, including radar interferometry (Jezek and others, 2011a), but analyses showed that radar tomography was best suited to obtaining robust, high-quality elevation data for the surface and base of the ice sheet as well as intensity images of both surfaces (Jezek and others, 2009; Paden and others, 2010; Wu and others, 2011). The data were demonstrated to be useful for understanding glacier dynamics (e.g. separating the effects of mass flux imbalance and melting rates on changes in ice-sheet elevation), as well as for investigating the glacial geomorphology of the modern ice-sheet bed (Jezek and others, 2011b).

In this paper, we compare and contrast radar data processed using advanced nadir sounding approaches with radar tomography. The data were collected over Isunnguata Sermia glacier in 2011 as part of OIB. Isunnguata Sermia is located in southwestern Greenland. It was selected by the OIB science team as a focus area for studying the glacier dynamics of a land-terminating glacier (www.bprc.osu.edu/ rsl/IST). As shown here, the two techniques provide powerful tools for characterizing the glacier base and for investigating the scale of structures that control local ice dynamics. We go on to integrate the radar topographies with other OIB datasets to investigate the physical properties of Isunnguata Sermia.

\section{DATA COLLECTION}

Isunnguata Sermia is located on the southwestern flank of the Greenland ice sheet (Fig. 1). The relatively small glacier extends into a now ice-free valley forward of the main 


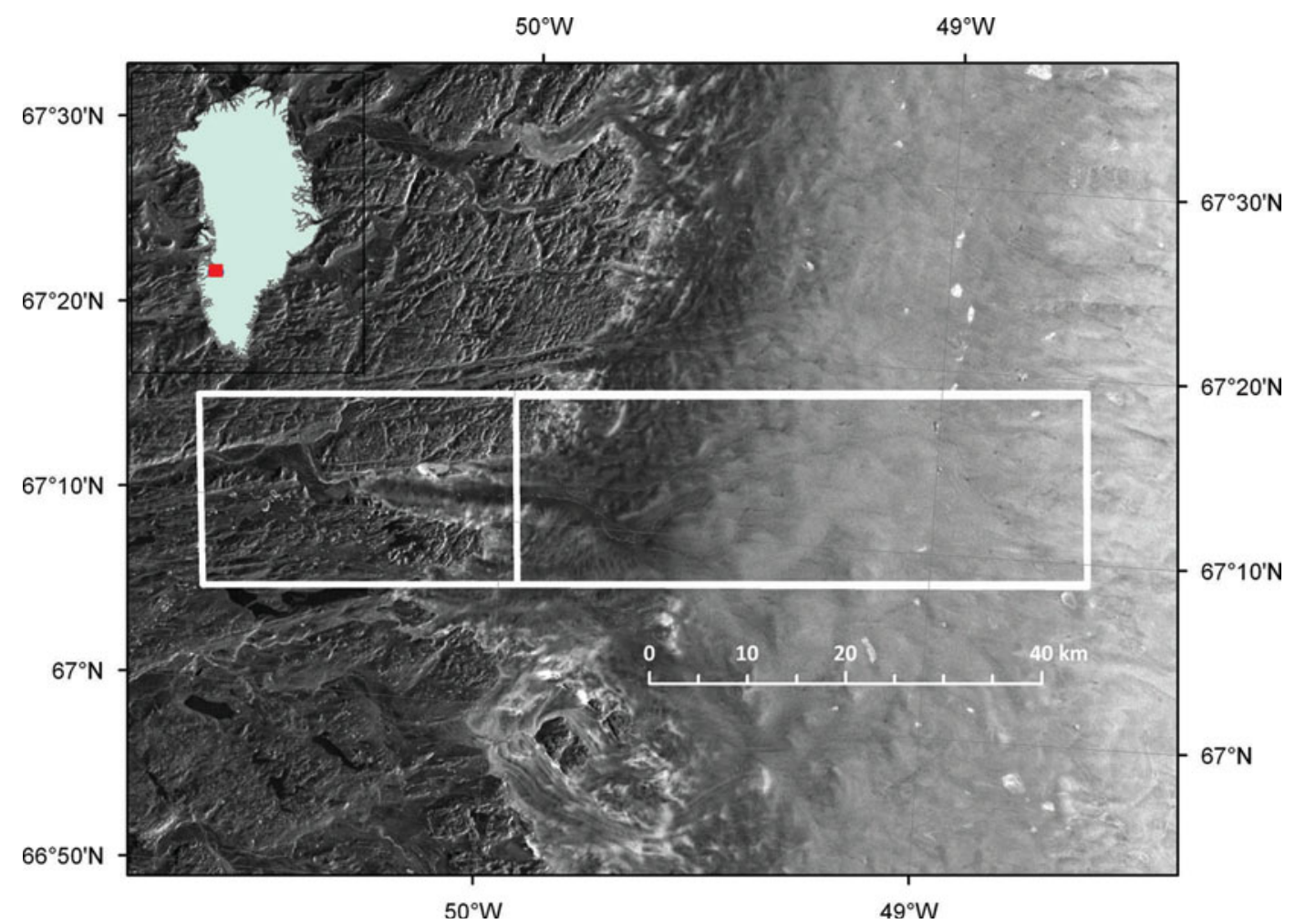

Fig. 1. Isunnguata Sermia shown in RADARSAT-1 SAR image. Combined left and right rectangles show the total area covered by closely spaced airborne flight tracks. The right rectangle isolates the approximate location where radar data were successfully collected. Inset map shows the location of Isunnguata Sermia in Greenland.

ice-sheet margin. The glacier terminates on land and so is less susceptible to rapid and large changes now experienced by marine-terminating glaciers such as Jakobshavn Isbræ.

Data used in this paper were collected by OIB on 13 and 16 April 2011 and along flight tracks spaced $\sim 500 \mathrm{~m}$ apart. The aircraft position was controlled automatically using onboard GPS, and deviations from the planned flight path were usually $<50 \mathrm{~m}$. The University of Kansas Multichannel Coherent Radar Depth Sounder (MCoRDS) and the Wallops Flight Facility Airborne Topographic Mapper (ATM) were used to obtain ice thickness and surface elevation data. Additionally, a Sander Geophysics airborne gravity meter was used to obtain free-air gravity anomalies.

\section{RADAR SYSTEM}

The MCoRDS radar system was operated on each flight segment. The primary MCoRDS instrument parameters are listed in Table 1 (Lei and others, 2010).

The radar system was equipped with 15 colinear dipole antenna elements. Seven elements were mounted under the fuselage of the P3 aircraft and four elements are mounted under each wing (Fig. 2). The middle seven antenna elements are used for both transmitting and receiving. The eight side elements are used for receiving only. For the seven transmit/receive channels, the receivers can be opened only after the radar waveforms are transmitted using a transmit/ receive switch.

In order to achieve a dynamic range of over $100 \mathrm{~dB}$ in the receiver, two radar waveforms are transmitted. The first waveform has a $1 \mu$ s chirp duration and is used to probe the ice-sheet near-surface with a small number of hardware integrations. The second waveform has $10 \mu$ s chirp duration, uses more integrations and is designed to capture data from deep or warm ice. When the echoes of these two waveforms are received, a lower gain is applied to the surface waveform echo because the surface echo is strong and a higher gain is applied to the base waveform since the bottom echo is usually weak. In this way a dynamic range of $100 \mathrm{~dB}$ can be achieved in the receiver with 14 bit analogue-to-digital converter units.

\section{CALIBRATION}

For a multichannel system like MCoRDS, phase and amplitude calibration are very important if either beam-focusing

Table 1. Key instrument parameters of MCoRDS built and operated by the University of Kansas

\begin{tabular}{|c|c|c|c|c|c|}
\hline Carrier frequency & Signal bandwidth & $\begin{array}{c}\text { Platform elevation above } \\
\text { surface }\end{array}$ & $\begin{array}{c}\text { Number of transmit } \\
\text { antennas }\end{array}$ & $\begin{array}{l}\text { Total receive } \\
\text { antennas }\end{array}$ & $\begin{array}{c}\text { Receive channels used for } \\
\text { the results }\end{array}$ \\
\hline $\mathrm{MHz}$ & $\mathrm{MHz}$ & $\mathrm{m}$ & & & \\
\hline 195 & 30 & $\sim 500$ & 7 & 15 & 7 \\
\hline
\end{tabular}




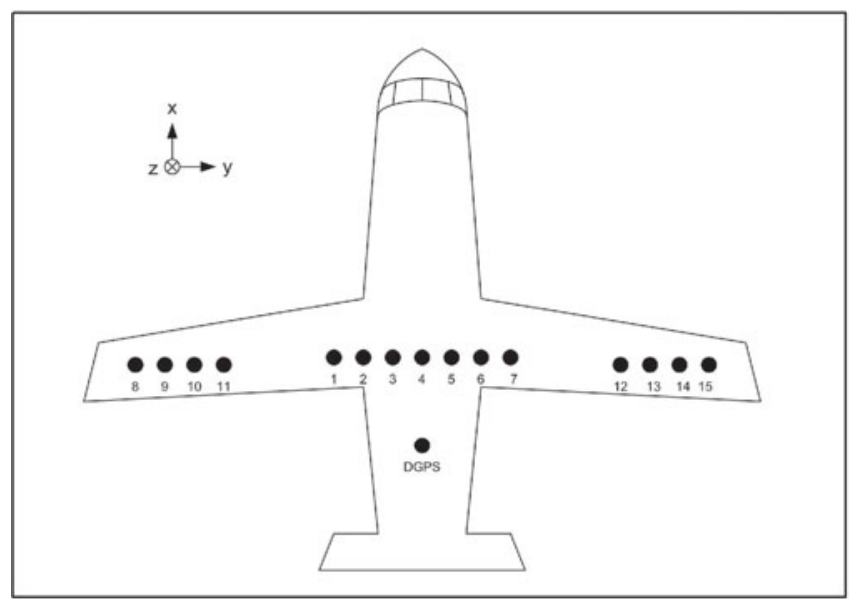

Fig. 2. Antennas and position geometry of MCoRDS P3 configuration. Originally intended to focus the radar beam and reduce surface clutter as required for nadir depth sounding, the multielement array proves ideal for tomographic processing.

or tomography are to be achieved successfully. Data calibration includes interchannel radiometric calibration, antenna geometric calibration and interchannel phase calibration.

In 2011, OIB collected calibration data over sea-ice areas with flight elevation $\sim 5 \mathrm{~km}$ above the sea-ice surface. The flight occurred on 9 April when the sea ice was relatively smooth and provided a good reference for phase calibration. The phase difference between any two channels is normally dependent on the environmental temperature of the radar. However, because MCoRDS is operated at low-frequency $\mathrm{VHF}$, the interchannel phase is a slow function of temperature. After calibration, the swath tomographic method (described below) is used to estimate the sea-ice surface elevation and the image magnitude. Prior to tomographic processing, signals from the left and right sides of the aircraft appear without discrimination (Fig. 3a). After processing, the nadir return is centralized in the image and the left-right side echoes are well separated (Fig. 3b).

\section{NADIR SOUNDING ICE THICKNESS}

The two primary challenges in nadir sounding of ice sheets are obtaining sufficient signal through the attenuating ice sheet and reducing surface clutter and side echoes, which can mask weak basal returns. MCoRDS is designed to overcome these challenges by using multiple antennas that increase the power density on the target and mute side echoes and surface clutter by electronic beam formation and steering. As part of OIB, the University of Kansas processes MCoRDS data and provides the data to the US National Snow and Ice Data Center (NSIDC). Processing procedures are described by Leuschen and Allen (2010) and summarized here for better understanding the comparison between nadir sounding and tomographic results.

Calibration data described above are used to apply channel compensations between each of the antenna phase centers (Leuschen and Allen, 2010). This includes time delay, amplitude and phase mismatches. Range resolution is achieved using pulse compression. Motion compensations for attitude and trajectory lever arm corrections are applied and then the data are SAR processed with an along-track spatial frequency window using frequency-wavenumber (F-K) migration. Data from multiple antennas are combined to enhance the basal return. Two methods are used to do this combination: (1) a simple beam-forming method, which sums radar profiles acquired from each antenna and is analogous to stacking traces; and (2) a minimum variance distortionless response (MVDR) method, which is described by Li and others (2013). Both algorithms use multi-looking or spatial incoherent power averaging of a neighborhood of pixels surrounding the image pixel being combined followed by along-track decimation. Lastly, echograms from low and high gain channels are combined to form a single image.

The resulting data can be displayed as individual amplitude waveforms or as intensity modulated displays. The former are useful for carefully picking the travel time of an echo, whereas the latter provide context for manual interpretation of the data. The layer tracking of ice surface and ice bottom reflections are manually driven processes with basic tools for partial automation. The tools used are
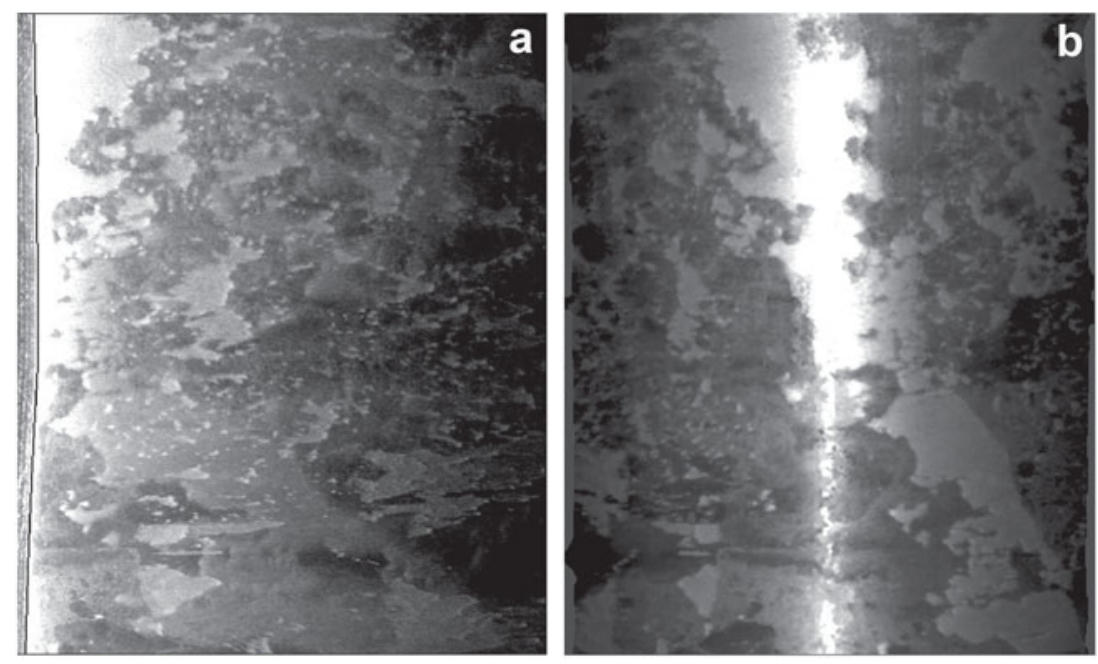

Fig. 3. (a) Range-referenced intensity image of the calibration site over sea ice. This range image displays the near-nadir return at the left margin of the image. The vertical along-track dimension is $14 \mathrm{~km}$. The horizontal slant range dimension is $3 \mathrm{~km}$ in air. (b) Tomographic image of the sea-ice surface after left-right separation. The along-track dimension is $14 \mathrm{~km}$ and the cross-track dimension in ground range is $12 \mathrm{~km}$. 


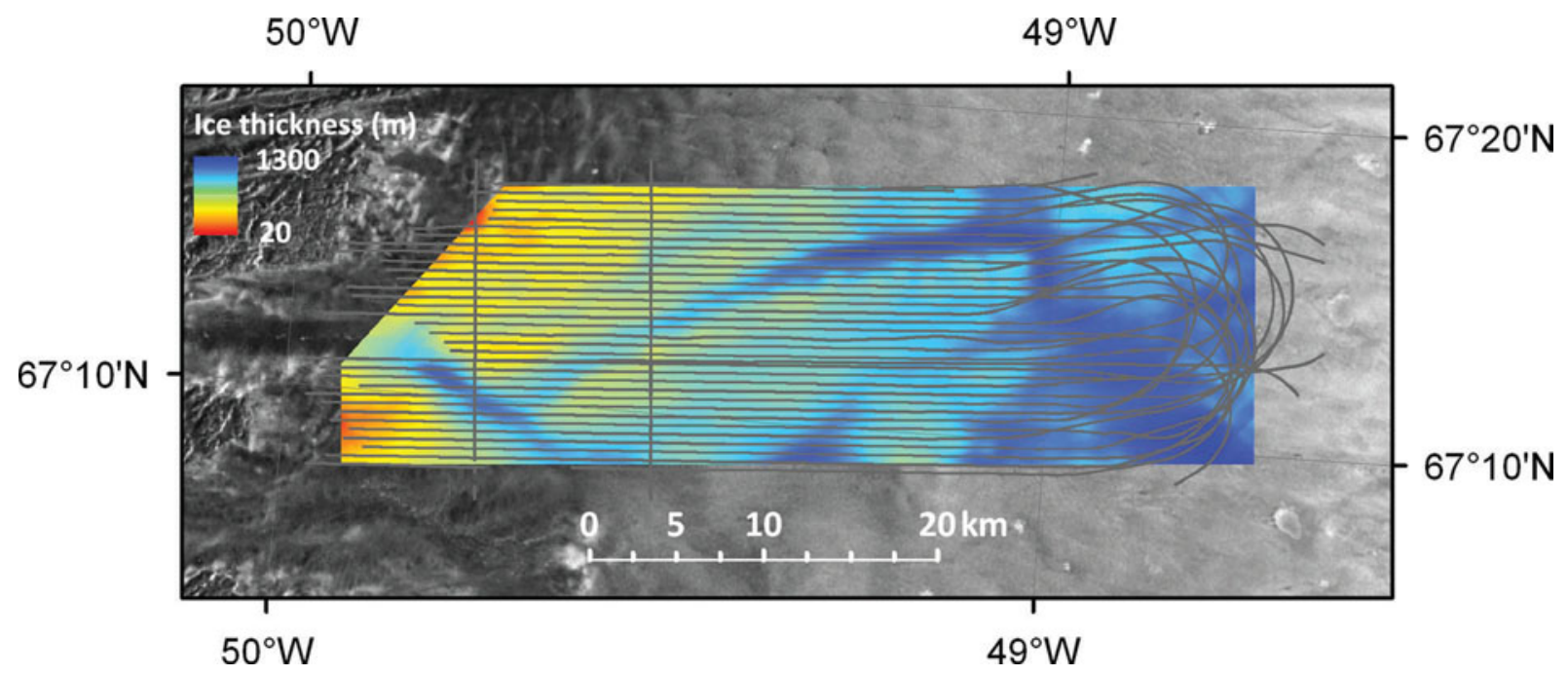

Fig. 4. Ice thickness model created using nadir ice-sounding data interpolated to a $50 \mathrm{~m}$ pixel grid. Gray curves show the location where valid ice thickness data were collected. The interpolated ice thickness data are superimposed on a RADARSAT-1 image of Isunnguata Sermia. The grid was clipped to include only the areas of dense radar coverage. The data shown here and in all succeeding figures are linearly scaled to color.

determined by the operator picking the data and include manual picking and interpolation, tracking the strongest return within a window, and tracking the leading edge of the strongest return. Various post-image processing methods (e.g. multi-looking and detrending) are used to better highlight features in the echogram as needed.

The radar was configured for nadir sounding observations during these experiments. Consequently near-nadir returns were emphasized, whereas off-nadir returns were attenuated. This improved the quality of along-track acquisitions but limited application of swath mode techniques. Nevertheless, as illustrated later, both data-processing approaches yielded useful results.

Operation IceBridge nadir measurements of ice thickness were downloaded from the NSIDC. These were interpolated to an ice thickness grid using kriging algorithms implemented in ArcMAP (Fig. 4). Five neighboring points selected from four equal quadrants were chosen to calculate a prediction map using ordinary kriging. Inspection of the selected points from within the data collection area showed that points were distributed both across and along track. The semivariogram was modeled with a spherical function computed using 100 lags of $100 \mathrm{~m}$ each. The prediction map was subsequently converted into a $50 \mathrm{~m}$ raster grid. The boundary of the calculated raster was masked to remove obvious interpolation distortions.

\section{RADAR-TOMOGRAPHY ICE THICKNESS}

Nadir ice-sounding provides one-dimensional thickness measurements of the ice sheets along the flight lines of the radar sounder. The along-track platform position is obtained by conventional GPS; radar timing provides the range measurement. However, at least four locations share these same geospatial characteristics: two points (left/right) each on the basal and surface layers will have the same range and cross-track azimuth. Discrimination among these points requires at least four additional independent measurements. MCoRDS provides these measurements by implementing a three-antenna array with 15 total dipole elements. By using phase-coherent tomographic (or angle-of-arrival) processing, one can discriminate among all ambiguities (basal and surface clutter) to obtain topographic maps of both the base and ice surface, together with radar reflectivity maps.

The formal basis for ice-sheet radar tomography and our implementation of the technique is described by $\mathrm{Wu}$ and others (2011). Essentially, we formulate the tomographic basal-ice imaging task as a problem of estimating signal arrival angles. The ice mass has two major interfaces: the upper surface interface, between the air and the ice mass, and the basal interface, between the ice mass and bedrock or basal water. Between the interfaces there are internal layers that originate from slight density changes or from changes in chemical impurities. Because the reflection of internal layers is highly specular, only their close nadir returns are significant but arrive at the receiver earlier than the bottom returns. Therefore the echoes from these internal layers are ignored in our analysis. When the radar signal reaches the air-ice interface, some of the energy is scattered back and some refracts through the interface and continues traveling through the ice mass. Some of the transmitted signal will scatter back towards the receiver from the basal interface. Simultaneous with the nadir echo arriving from the bedrock, the receiver may also detect the surface reflected signal from both the left and right sides of the sensor. Off nadir, there may also be simultaneous echoes from the base originating from the opposite sides of the airplane. In addition, there will be thermal and other noise sources. Radar tomography allows for the separation of these various returns given a sufficient number of independent receiver channels.

In earlier work (Wu and others, 2011), we found that tomographic estimates of ice-sheet surface elevation compared to within $5 \mathrm{~m}$ rms of Ice, Cloud and land Elevation Satellite (ICESat) elevation data. We also compared tomographic data with independent nadir-radar measurements acquired orthogonal to the tomography flight directions. The estimates compared favorably to within $14-18 \mathrm{~m}$ rms. We noted then that the tomographic data contained artifacts near nadir. This was because the earlier algorithm sought to discriminate between left- and right-side arrivals even given, as is the case at nadir, that there is only one signal. For the 


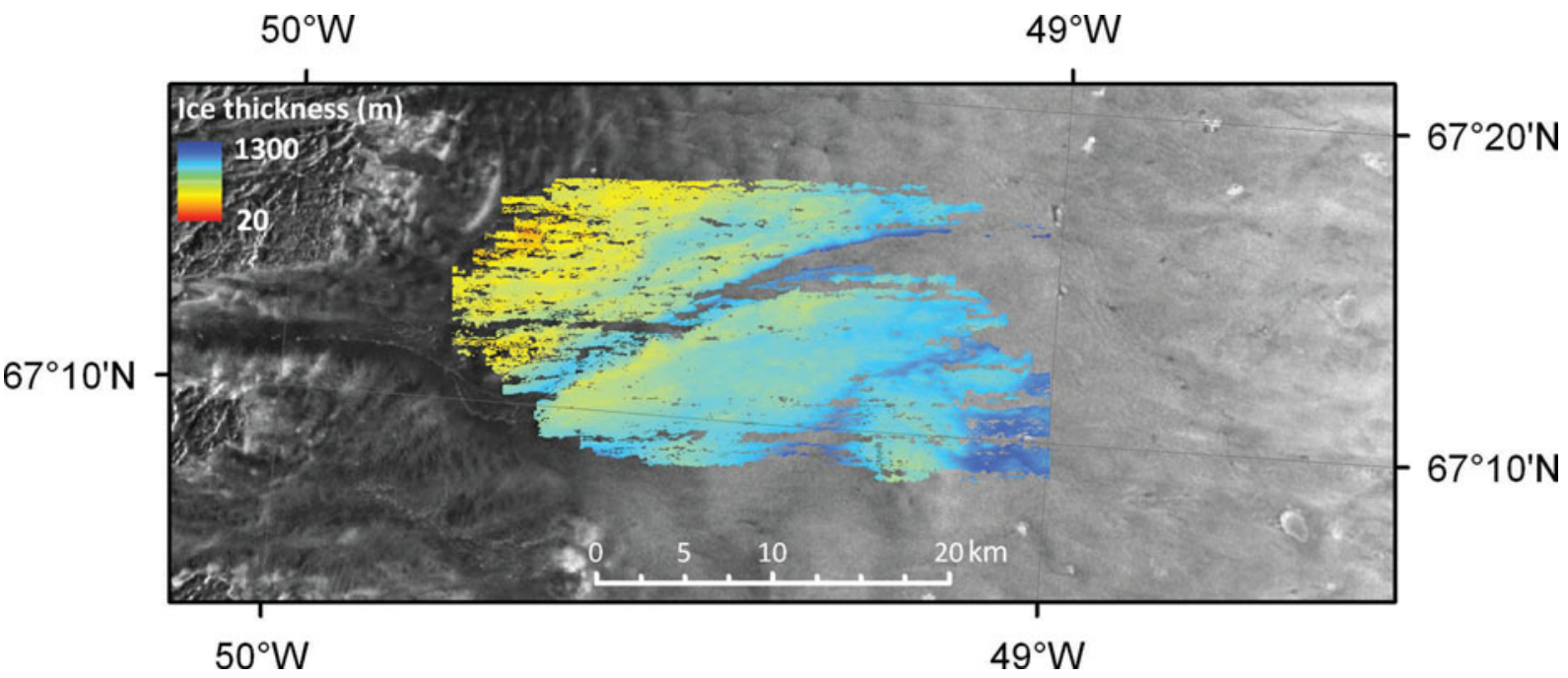

Fig. 5. Radar tomography ice thickness estimate of Isunnguata Sermia. Data are superimposed on a RADARSAT image.

data presented here, the processing algorithm was modified to seek only one arrival near nadir. This eliminates the artifacts and, as discussed later, improves the comparison between the coincident tomographic and nadir data to a comparable level.

There was a total of 27 processed tracks of data collected over Isunnguata Sermia on 13 and 16 April 2011. The processing steps are range compression, time-domain azimuth compression and tomographic processing for each track. After the ice thickness is generated, a surface digital elevation model (DEM) compiled from OIB ATM data (discussed below) is used to generate the bottom topography. Finally all the tracks of ice thickness and bottom elevation measurements are mosaicked (Fig. 5). Gaps appear in the map for several reasons including low signal level, shadow and layover. Optimization for nadir sounding also means the off-nadir returns will be preferentially weakened. Nadir tracking, as shown below, fills in some of the gaps because manual tracking can often be accomplished with lower signal levels and discontinuous echoes can be interpolated given the overall context of the segments.

\section{SUBGLACIAL TERRAIN}

To construct models of subglacial relief, we subtracted the ice thicknesses from a DEM of the surface. We constructed the DEM (50 m post spacing) for the Isunnguata Sermia surface and its surrounds. ATM Qfit data (Krabill, 2010) were downloaded from the NSIDC for flights that occurred on 13 and 16 April 2011. ATM is a scanning laser altimeter. To reduce the total data volume, only data acquired at the aft, left and right azimuth angles of the scan were selected. The data were converted to polar stereographic coordinates and then interpolated using the same method and parameters as described for the interpolated ice thickness data. The $50 \mathrm{~m}$ grid was masked to isolate data over the region of interest and remove obvious boundary-region artifacts (Fig. 6).

The tomographic ice thickness data were subtracted from the surface DEM to construct the basal topography. Similarly, the interpolated nadir-data-derived ice thicknesses were subtracted from the surface topography to construct a second estimate of the base (Fig. 7). The nadir data yield a more extensive estimate of the basal topography than the tomographic result, first because the nadir data are interpolated to a continuous grid, second because the nadir signal is stronger than the off-nadir returns and third because manual interpolation between weak echoes along the flight track can successfully bridge gaps. Both approaches reveal a terrain characterized by undulating highlands to either side of a deep channel that runs northeast-southwest into the main trunk of Isunnguata Sermia. Interpolated nadir data reveal a $>600 \mathrm{~m}$ deep trough that channels flow northwest towards the westward terminus of the glacier. A 300 m deep channel, visible in both maps, strikes northeast before intercepting the main trunk. The channel intercepts another northwest-southeast-striking 150-200m deep channel farther upstream.

Basal topography maps estimated from tomography and interpolation of nadir data were differenced in areas of overlap. The mean difference is $4 \mathrm{~m}$ with a standard error of $31 \mathrm{~m}$. Profiles of the along-track nadir data are taken as the reference and selected based on continuity of the tomography map over the length of the profile (Fig. 8). The nadir data are compared with the interpolated nadir data and the tomography data along the three nadir sounding tracks (Fig. 9). For the central line and after interpolating data to a common geographic location, the point-by-point rms difference between the nadir data and the tomographic data is $\sim 16 \mathrm{~m}$, similar to the measure reported by $\mathrm{Wu}$ and others (2011). The tomography estimate disagrees by $\sim 50 \mathrm{~m}$ from the other two datasets near $18 \mathrm{~km}$ along the northerly line. Disagreement between the tomographic data and the nadir data is often due to errors in tracking the ice bottom in steep terrain. Specifically, when a strong off-nadir reflection occurs, the nadir sounding method may not perfectly reject this side echo and the analyst tracking the ice bottom may incorrectly interpret this as the nadir echo or it may be the only echo available. Tomography better handles this situation because it generally has finer cross-track resolution and properly resolves the side-looking and nadir echoes. In fact, strong side echoes will be better resolved because they are stronger and have a higher signal-to-noise ratio (SNR).

The three basal topography datasets contain spatial wavelengths at the $5-10 \mathrm{~km}$ scale with similar amplitudes (Fig. 9). Shorter wavelength (1-2 km) undulations along the flight direction are evident in the tomography and nadir data. 


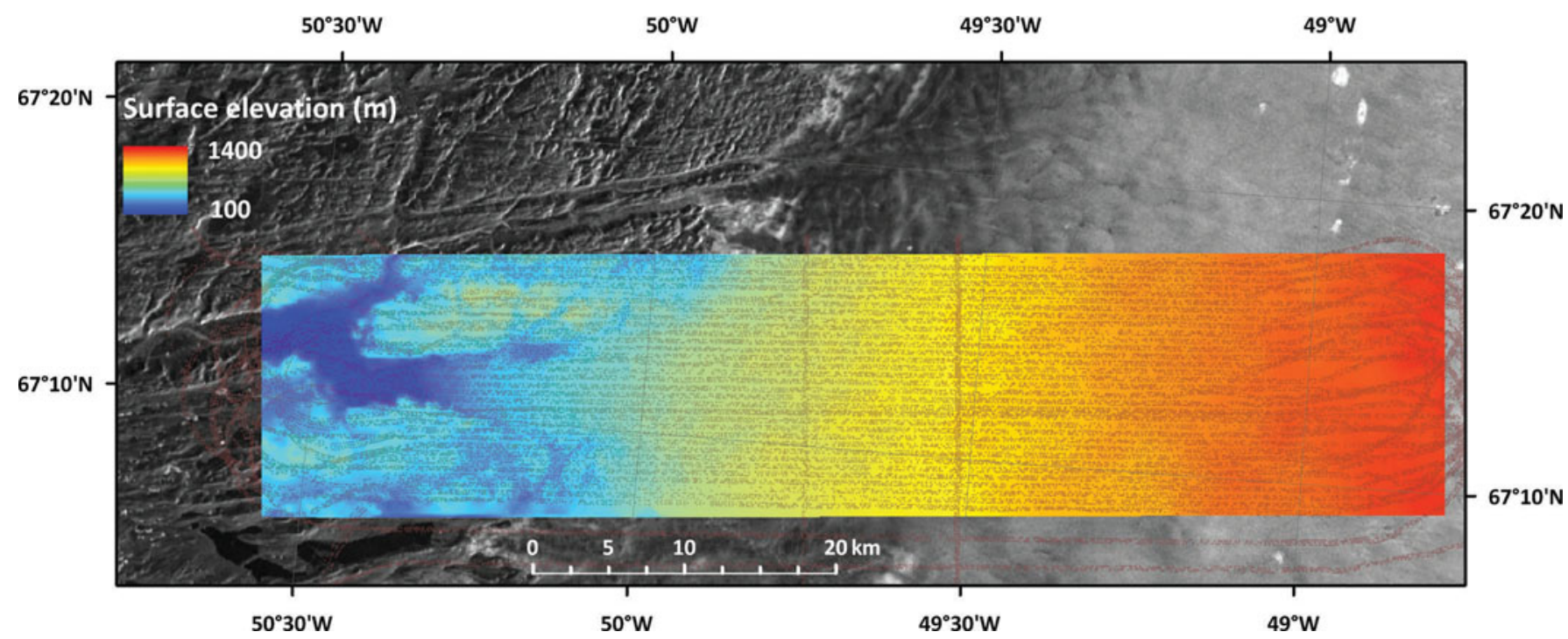

Fig. 6. ATM elevation data points (red and brown dots) selected for DEM construction. DEM is superimposed on a RADARSAT-1 image. The topography is highest on the upstream portion of the ice sheet $(>1300 \mathrm{~m})$ and gently descends to the ice margin. The sediment-filled valley forward of the glacier terminus is near $100 \mathrm{~m}$ elevation (relative to the World Geodetic System 1984 ellipsoidal elevation (WGS84)).

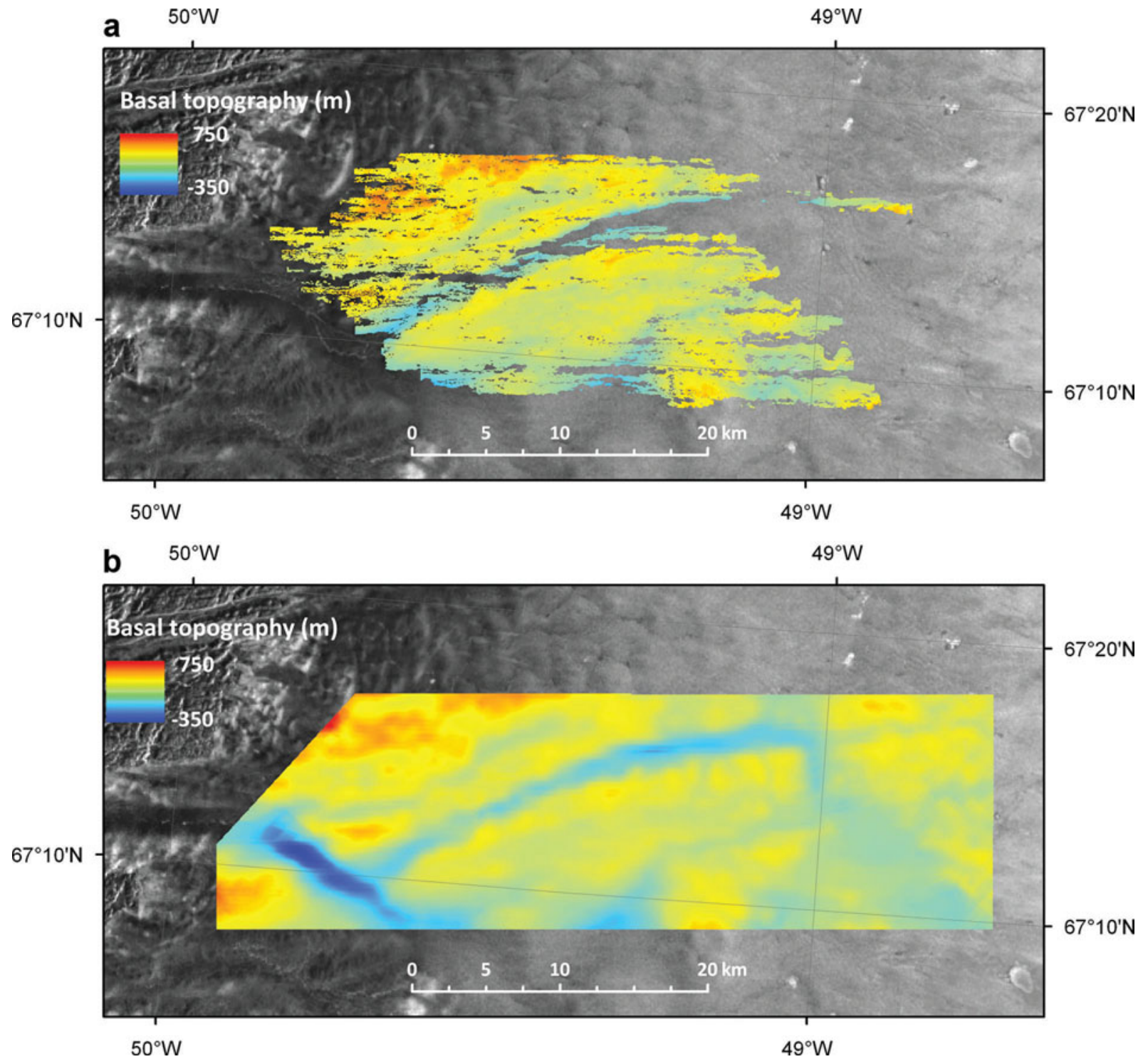

Fig. 7. (a) Basal topography estimate of Isunnguata Sermia computed by subtracting tomographic ice thickness from surface elevation mode. (b) Basal topography estimated by interpolating nadir ice thickness data and subtracting from a DEM of the surface. 


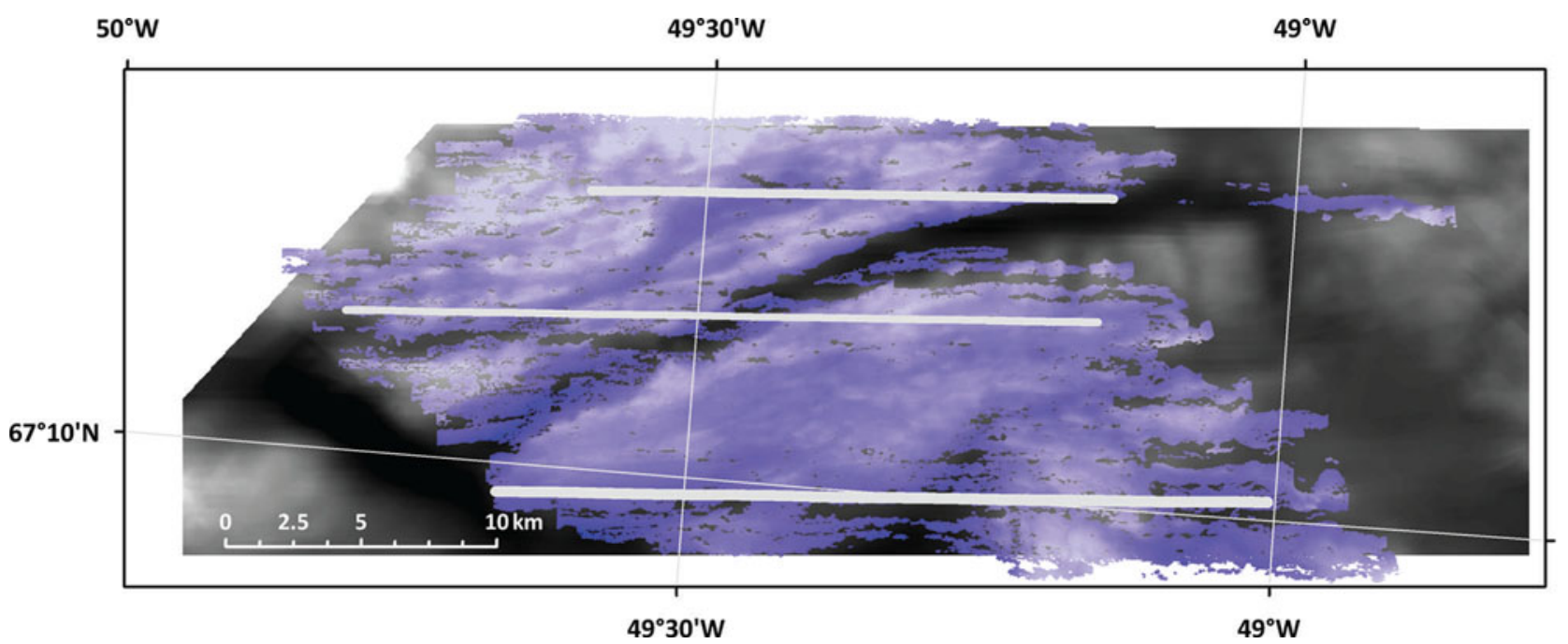

Fig. 8. Tomography-derived basal topography (shaded blue) overlaid on interpolated topography. Three nadir sounding tracks (northern, central and southern lines) were extracted along the thick gray lines, which were chosen to avoid gaps in the tomography data.

Evidence in support of short wavelength topography comes from inspection of ATM-derived elevation data collected forward of the glacier snout (Fig. 9). Fourier transform of the conditioned (zero-meaned, Hanning-weighted and padded) rock surface profile shows that there are spectral peaks at 1.6, 2.7 and $3.6 \mathrm{~km} \mathrm{cycle}^{-1}$. Detection of longer wavelengths is limited by the length of the record. Fourier transform of the conditioned tomographic profile along the
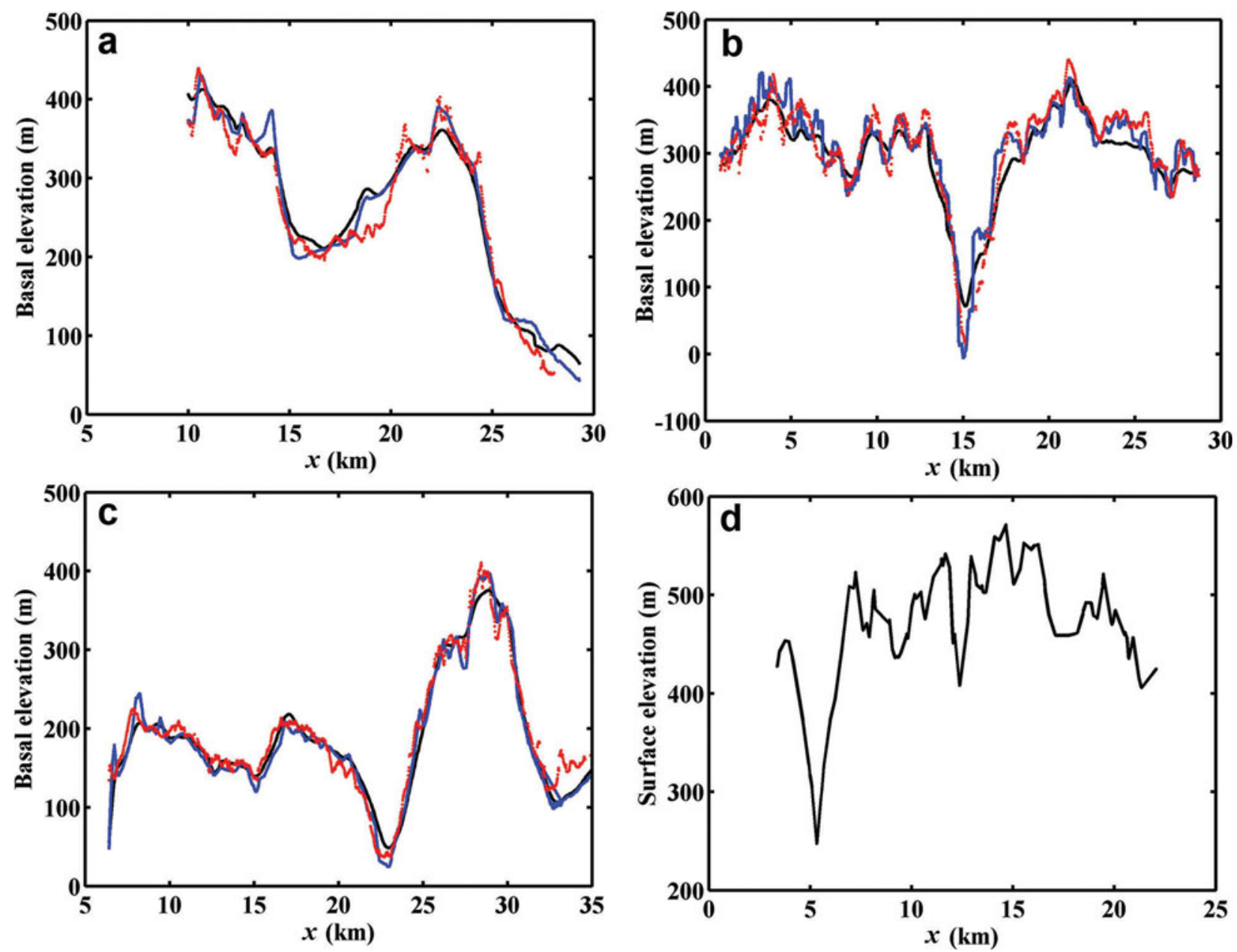

Fig. 9. Comparisons of basal topography constructed from tomography (red), nadir data (blue) and interpolated nadir data (black) along the (a) northerly, (b) central and (c) southerly profile lines in Figure 8 . The horizontal coordinate is the $x$ polar stereographic coordinate along the profile and the values are offset by $-2.1 \times 10^{5} \mathrm{~m}$ for display purposes. (d) ATM-derived surface elevation along the deglaciated terrain forward of the glacier illustrates the similarity between the glaciated and deglaciated basal topography. The horizontal coordinate is offset by $-2.4 \times 10^{5} \mathrm{~m}$. ATM data positions are shown in Figure 6 by the red dots that lie along the northwestern boundary of the grid. 


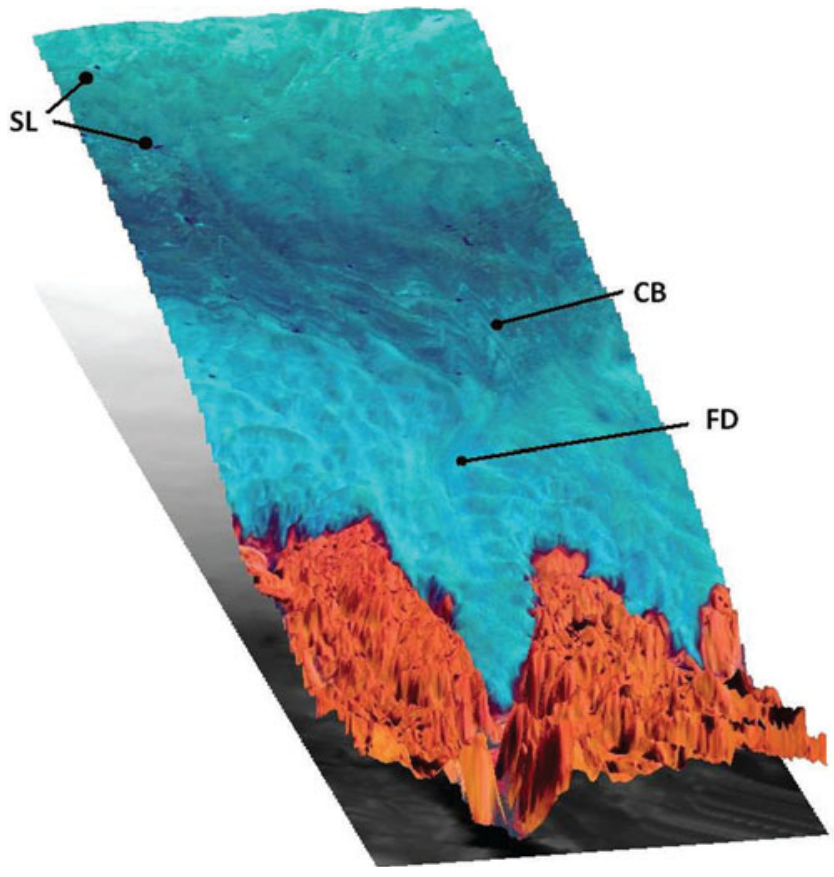

Fig. 10. Perspective of Isunnguata Sermia (blue). This August 2010 Landsat-7 image is overlain on the surface elevation model. Surface lakes (SL) $\sim 1 \mathrm{~km}$ across are distributed in the upper half of the image. Layering within the ice sheet appears as curvilinear bands (CB) that run transverse across the ablation region of the glacier. Flow direction (FD) can be determined from the curves that wind down the center of the glacier. Exposed rock surface (brown) and lakes (black patches) extend westward away from the glacier terminus. There is a $10 \times$ vertical exaggeration.

central line also shows a strong spectral peak at $1.6 \mathrm{~km}$ cycle $^{-1}$. There is a weaker peak at $2.1 \mathrm{~km}_{\text {cycle }}{ }^{-1}$ followed by peaks at 3.8 and $10.0 \mathrm{~km} \mathrm{cycle}^{-1}$. There is a strong peak at $10 \mathrm{kmcycle}^{-1}$ in the measured nadir data followed by spectral peaks at 3.9, 2.1 and $1.6 \mathrm{~km} \mathrm{cycle}^{-1}$; however, the shorter wavelength components are poorly defined. As expected, the interpolated data are smoothed relative to the tomography and nadir data. There remains a strong spectral peak at $1.5 \mathrm{kmcycle}^{-1}$, but the peak at $\sim 2 \mathrm{~km}$ cycle $^{-1}$ is muted at best and at $3.8 \mathrm{~km}$ is nearly hidden in the spectral slope leading up to the expected peak at $10 \mathrm{~km} \mathrm{cycle}^{-1}$.

As noted above, the tomographic and interpolated topography estimates are consistent to better than $10 \mathrm{~m}$ on average, though the interpolated surface is smoother than the tomographically derived surface. Agreement is a consequence of the exceptionally fine across-track spacing $(\sim 500 \mathrm{~m})$ achieved in this survey. Unlike the continuous surface created by interpolating the nadir data, the tomographic surface is less extensive and contains small gaps, but the tomographic surface better retains short-wavelength roughness in the along-track direction and, as shown by Wu and others (2011), in the cross-track direction as well. In summary and not unexpectedly, different methods of processing the data have advantages and disadvantages. So we rely on the strengths of each method to investigate glacier processes in Section 8.

\section{DISCUSSION}

Isunnguata Sermia flows through a deep bedrock trough. The glacier terminates in a sediment-filled valley that carries away summer meltwater. A perspective view of Isunnguata Sermia is shown in Figure 10, which illustrates the different environs of the glacier. An August 2010 Landsat-7 image obtained from the US Geological Survey (USGS) is overlaid on the surface elevation model. Flow directions upstream on the glacier are noticeable as weak longitudinal flow stripes embedded within the center of the generally undulating surface. Surface lakes on the ice sheet appear as small dark spots, which correspond well with the positions of surface depressions. Lateral curvilinear bands in the center of the image are exposed layers within the ice in this region of strong surface ablation.

Details of the surface topography are shown in Figure 11. TerraSAR-X SAR interferometry data collected by the German Aerospace Center in support of OIB (personal communication from D. Floricioiu, 2011) in 2009 provide surface velocities (courtesy of I. Joughin). Velocities range from $\sim 20 \mathrm{~m} \mathrm{a}^{-1}$ near the terminus to $\sim 120 \mathrm{~m} \mathrm{a}^{-1}$ in the channel feeding Isunnguata Sermia. In the eastern part of the image, velocities bear to the west more or less orthogonal to the surface contours. In the south central part of the scene, the

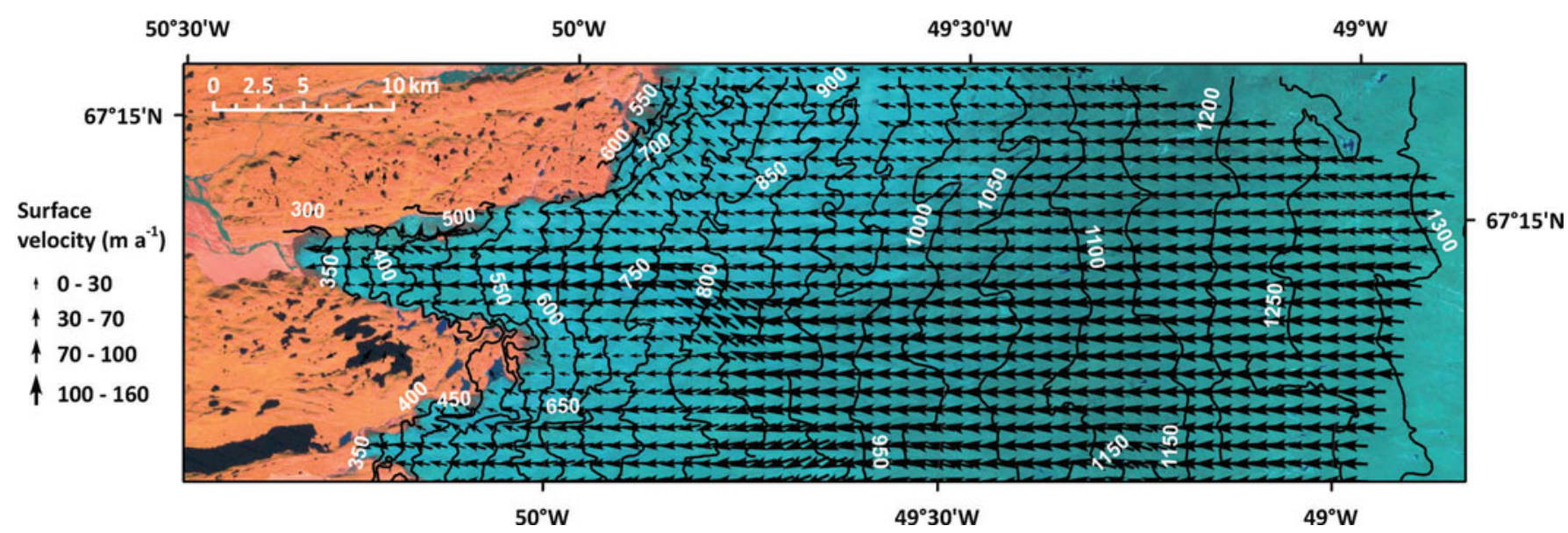

Fig. 11. Surface elevation contours (50 m interval) superimposed on a Landsat-7 image of Isunnguata Sermia. The surface elevation increases from $\sim 300 \mathrm{~m}$ above the ellipsoid near the snout to $\sim 1350 \mathrm{~m}$ elevation near the upstream end of the study area. Surface velocity vectors are from TerraSAR-X interferometry (courtesy of I. Joughin). Velocities range from $\sim 20 \mathrm{ma}^{-1}$ near the glacier terminus to $\sim 120 \mathrm{~m} \mathrm{a}^{-1}$ within the channel feeding Isunnguata Sermia. 


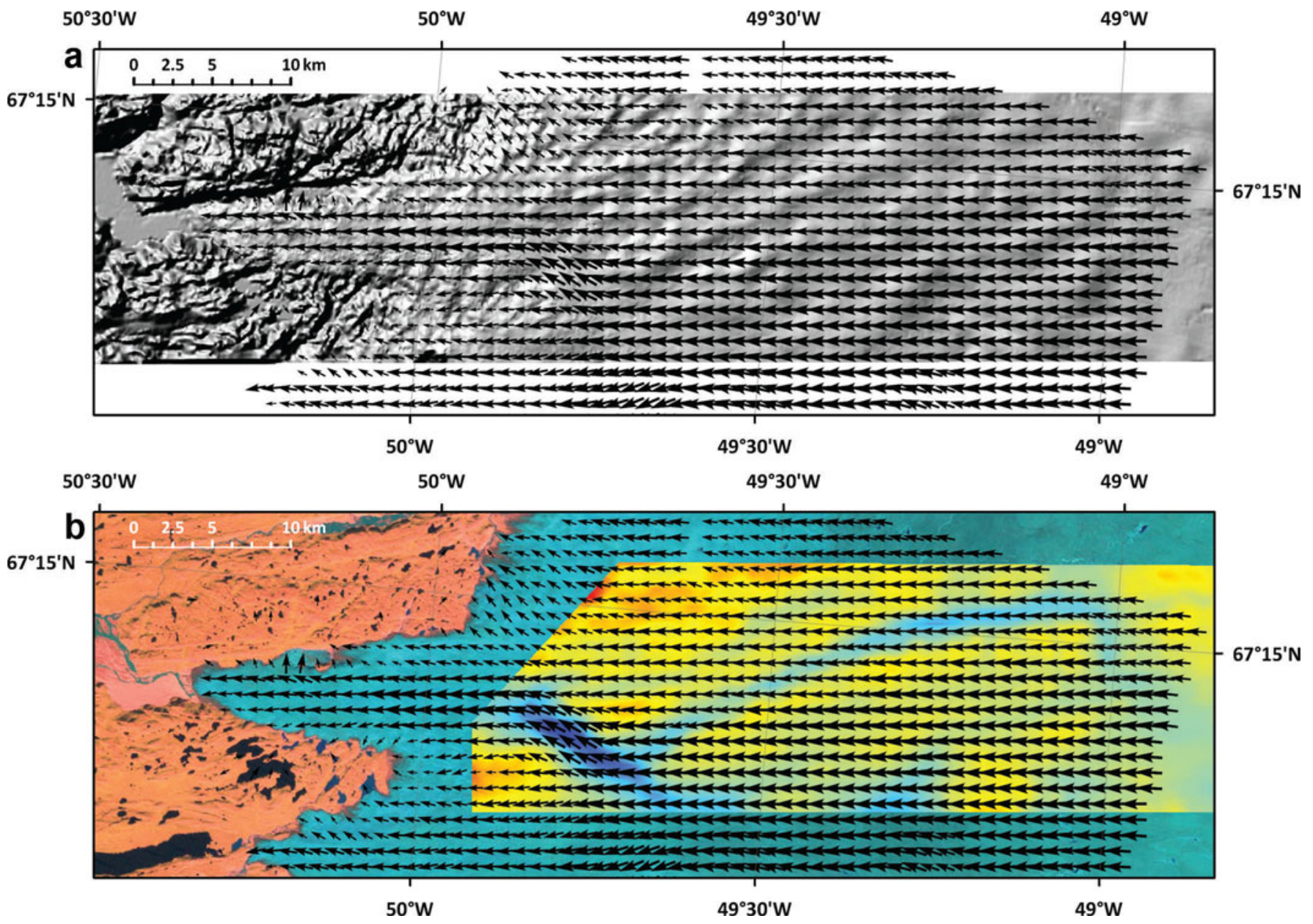

Fig. 12. (a) Velocity vectors from Figure 15 overlaid on a hill-shaded model of the Isunnguata Sermia surface topography. (b) Surface velocities overlaid on the basal topography model assembled from interpolated nadir sounding MCoRDS radar data. Velocity arrows are scaled as in Figure 11.

effect of the deep subglacial channel is seen to reorient the velocities to the northwest and then down towards the terminus of the glacier. Even slow-moving ice along the more stagnant margins flows in a direction orthogonal to the contours, adding confidence to the quality of the velocity dataset.

The velocity field is little influenced by basal topography other than the deepest trough feeding the terminus. This is illustrated in Figure 12 where velocity data are superimposed on a hill-shaded relief map of the surface elevation and on the basal topography, respectively. Many of the northwest- and northeast-striking lineaments that intersect in a checkerboard pattern noticeable in both the subglacial topography and the surface topography have little influence on the orientation of the surface velocity field.

Surface elevation and ice thickness data were resampled to $1 \mathrm{~km}$ grids to calculate surface slopes and driving stresses on the order of one ice thickness. Elevation data used here are relative to the ellipsoid. The $2 \mathrm{~m}$ geoid undulation, which trends east-west in this area, was ignored in the calculation. Driving stresses are defined in the usual way as

$$
\tau_{\mathrm{d}}=\rho g H \frac{\partial h}{\partial s}
$$

where $\rho$ is the ice density, $g$ is the acceleration due to gravity, $H$ is the ice thickness, $h$ is the surface elevation and $s$ is the distance downslope along the surface (Van der Veen, 1999). Driving stresses range from 10 to $240 \mathrm{kPa}$ (Fig. 13). Driving stress is on average $\sim 104 \mathrm{kPa}$. Highest driving stresses $(\sim 220 \mathrm{kPa})$ are generally associated with the thicker ice. Lowest driving stresses (10-20 kPa) are correlated with small surface lakes, presumably because slopes are low in the depressions where lakes are likely to form.

The relatively uniform orientation of the velocity field, at least in the eastern part of the study area, and the likelihood that lateral forces are small for this relatively slow-moving glacier suggest that a simple laminar flow model is appropriate for describing the gross behavior of the upstream area. The theoretical surface velocity $\left(U_{s}\right)$ for the case where basal drag dominates the resistive stresses is

$$
U_{\mathrm{s}}=\frac{2 A H}{n+1} \tau^{n}+U_{\mathrm{b}}
$$

where $U_{\mathrm{b}}$ is the basal sliding velocity (Van der Veen, 1999). Using the measured ice thickness, the driving stress as computed above, a warm value for $A\left(2 \times 10^{-17} \mathrm{kPa}^{-3} \mathrm{a}^{-1}\right)$ and $n=3$, the average of the first term is $\sim 60 \mathrm{~m} \mathrm{a}^{-1}$ less than the measured surface velocity. The difference can be explained by attributing $\sim 50 \%$ or less of the surface velocity to basal sliding. Our estimated contribution of basal sliding is higher than that modeled by Brinkerhoff and others (2011). The acknowledged simplifications in our analysis and also the important differences between our measured basal topographies and those used by Brinkerhoff and others (2011) together may account for the discrepancy. 


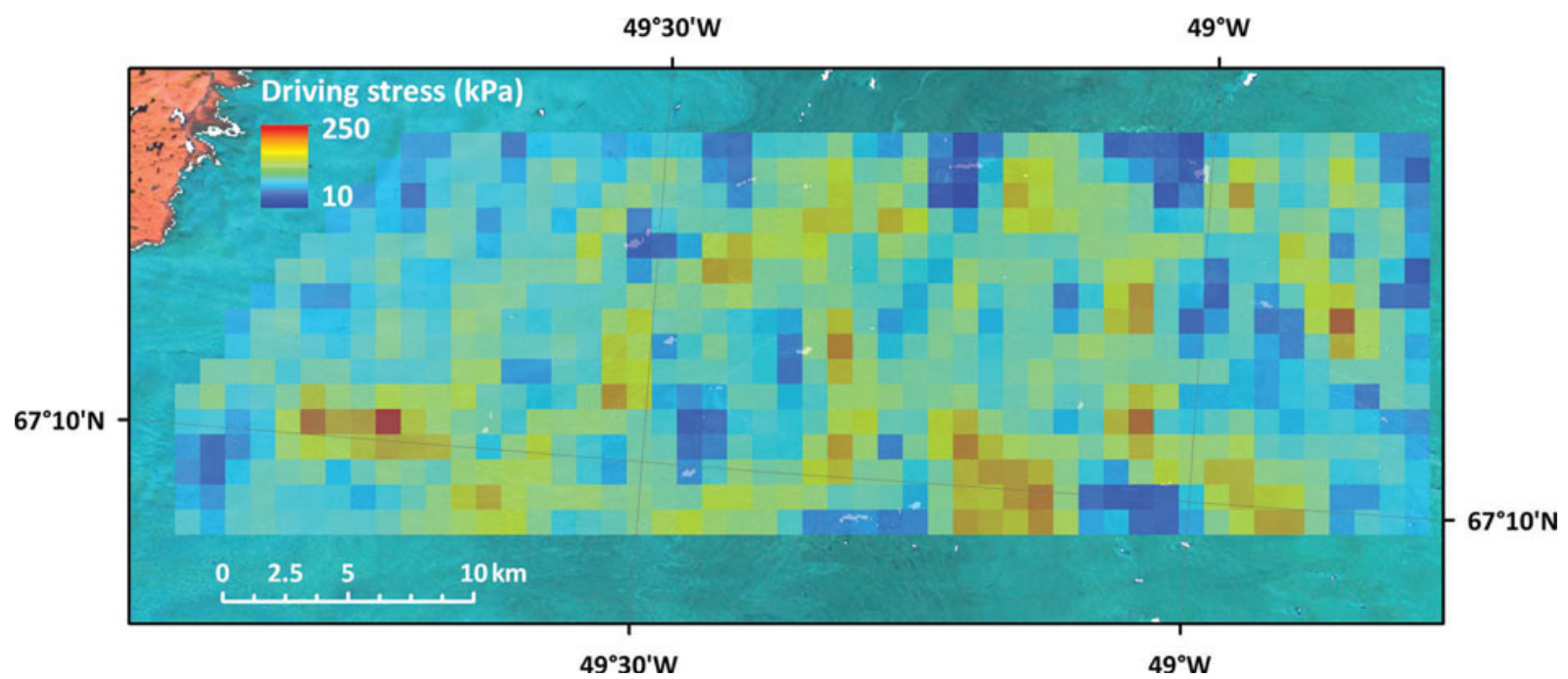

Fig. 13. Driving stress overlaid on Landsat-7 image. Driving stress map is partially transparent. Lakes (white patches) were classified in the Landsat-7. Locations of the lakes generally correspond to locations of low driving stress.

Subglacial terrain adjacent to the troughs consists of hilly terrain reminiscent of the deglaciated coastal regions of Greenland. To further compare the proglacial and subglacial terrain maps, we hill-shaded the surface and subglacial DEMs compiled from ATM-interpolated nadir data and radar tomographic data, respectively (Fig. 14). As quantitatively shown earlier using profile data, the tomographic basal topography map seems little different from that of the exposed rock forward of the ice front. The map data in Figure 14 extend this conclusion to two dimensions (2-D). Continuity of the subglacial geology across the glacier terminus is evidenced by free-air gravity anomalies (Cochran and Bell, 2010) (Fig. 15). There are noticeable north-south anomaly gradients, but east-west anomaly gradients across the terminus are weak. Consistent with the topography data, strongest negative anomalies are associated with the glacier troughs and sediment-filled valleys. Similarity between the proglacial terrain and the tomographically derived subglacial topography suggests that at least at the scale of the measurements (50 $\mathrm{m}$ pixels), erosional processes acting on the bed of the modern ice sheet are largely unchanged from those that operated on the now deglaciated area to the west.

\section{SUMMARY}

Nadir sounding and tomography processing techniques are both useful for investigating different geophysical aspects of the radar measurements. Nadir sounding data, improved by surface clutter and side echo reduction, can be interpolated to build spatially extensive grids of detailed subglacial topography including sounding of deep subglacial troughs. A limitation of this approach is that the nadir data must be interpolated to build the grid and interpolation inherently smooths the data. Moreover, multiple closely spaced flight lines are required to assemble a high-fidelity grid and only in rare instances, as here, is that logistical requirement achievable. Radar tomographic techniques operating on the same data can be used to directly sample in 2-D and

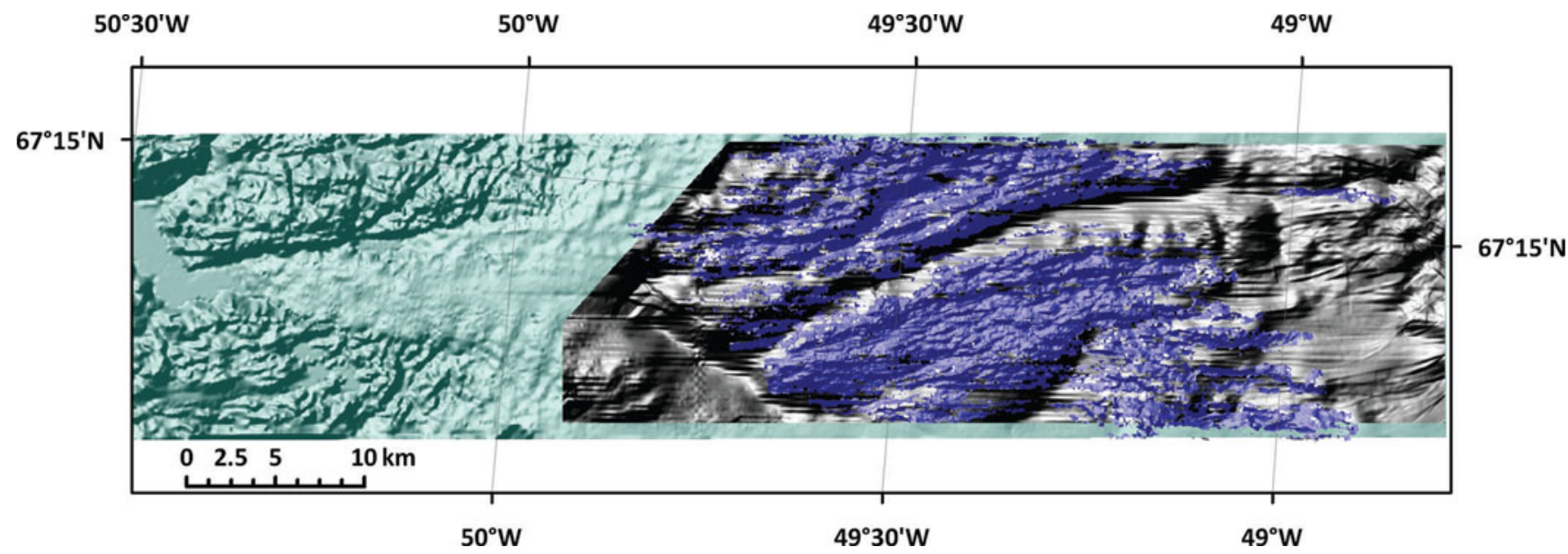

Fig. 14. Hill-shaded model of the tomography-derived basal topography (dark blue) overlaid on a hill-shaded model of the interpolated nadir data topography (gray). In turn, these are overlaid on a hill-shaded model of the ice-sheet exposed rock surface (light blue). The vertical exaggeration of each model is $10 \times$. Residual interpolation artifacts in the interpolated surface are noticeable at this vertical exaggeration (far right portion of the image). 


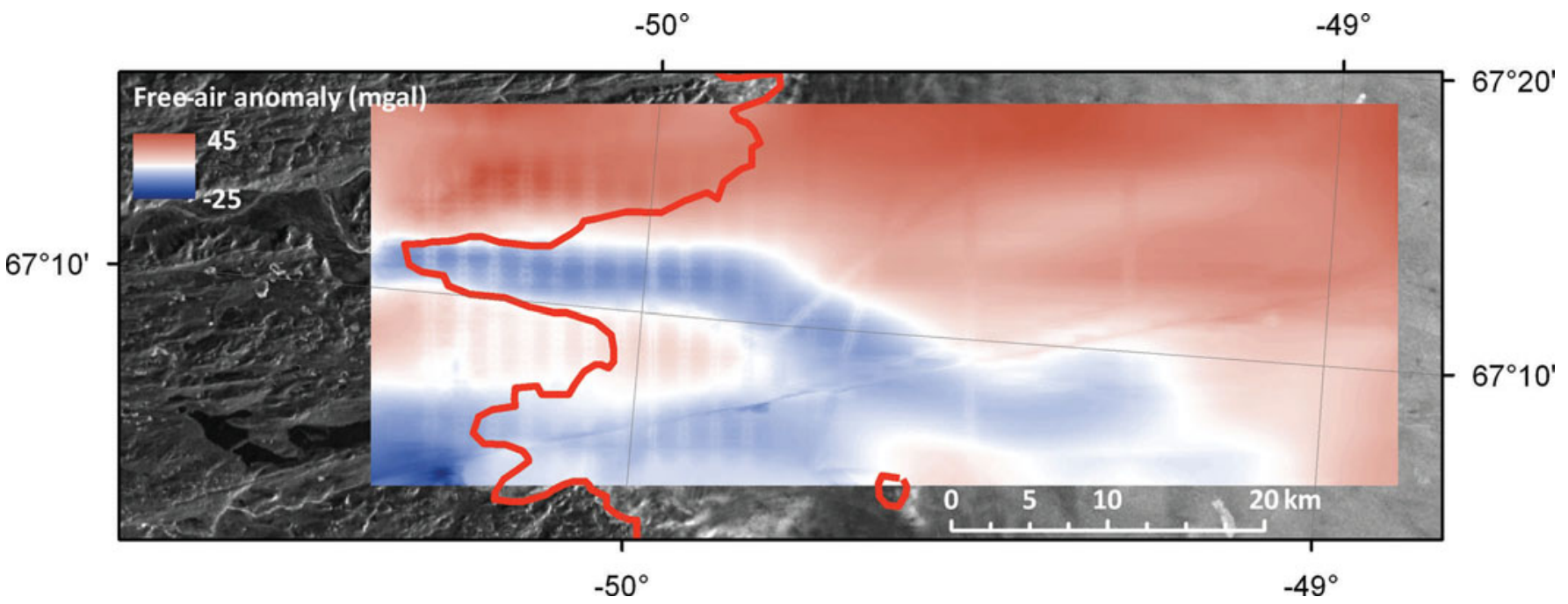

Fig. 15. Interpolated free-air gravity anomalies. Flight-line orientation artifacts are visible in the left portion of the image. Negative anomalies are confined to the proglacial valleys and subglacial channels. There is little difference between the anomaly magnitude up-glacier of the terminus (red curve) and the anomaly magnitude over the deglaciated terrain.

retain high-frequency signals in the terrain. Flight-line spacing can also be increased, making tomography more practical. However tomography requires good SNRs to obtain reliable off-nadir estimates. From past experience (Wu and others, 2011), an SNR better than $0 \mathrm{~dB}$ for each channel is desirable for tomography processing.

When applied in this study of Isunnguata Sermia, interpolated nadir data capture an intersecting network of deep subglacial troughs. Upstream of the main glacier trunk, the troughs have little influence on the direction of ice flow, which is governed in about equal measures by basal sliding and creep. At finer scales, the tomography data capture details of short-wavelength topography that compares favorably with the exposed terrain west of the glacier terminus. Consequently the processes currently shaping the bed of this relatively slow-moving land-terminating glacier are likely to be the same as those which once shaped the rocky terrain now forward of the glacier terminus.

\section{ACKNOWLEDGEMENTS}

This research was supported as part of NASA's Operation IceBridge project and also by NASA's Cryosphere Program. The University of Kansas also received support from the US National Science Foundation through the Center for Remote Sensing of Ice Sheets. This research was (partly) carried out at the Jet Propulsion Laboratory, California Institute of Technology, under a contract with NASA. Many helpful suggestions were received from two anonymous reviewers.

\section{REFERENCES}

Arthern RJ, Winebrenner DP and Vaughan DG (2006) Antarctic snow accumulation mapped using polarization of $4.3 \mathrm{~cm}$ wavelength microwave emission. J. Geophys. Res., 111(D6), D06107 (doi: 10.1029/2004JD005667)

Bogorodsky VV, Bentley CR and Gudmandsen PE (1985) Radioglaciology. D. Reidel, Dordrecht

Brinkerhoff DJ, Meierbachtol TW, Johnson JV and Harper JT (2011) Sensitivity of the frozen/melted basal boundary to perturbations of basal traction and geothermal heat flux: Isunnguata Sermia, western Greenland. Ann. Glaciol., 52(59), 43-50 (doi: 10.3189/ 172756411799096330)

Bull C and Hardy JR (1956) The determination of the thickness of a glacier from measurements of the value of gravity. J. Glaciol., 2(20), 755-763

Cochran JR and Bell RE (2010) IceBridge Sander AIRGrav L1B geolocated free air gravity anomalies [updated 2011]. National Snow and Ice Data Center, Boulder, CO. Digital media: http:// nsidc.org/data/iggrv1b.html

Diehl TM, Holt JW, Blankenship DD, Young DA, Jordan TA and Ferraccioli F (2008) First airborne gravity results over the Thwaites Glacier catchment, West Antarctica. Geochem. Geophys. Geosyst., 9(Q4), Q04011 (doi: 10.1029/2007GC001878)

Ettema J and 6 others (2009) Higher surface mass balance of the Greenland ice sheet revealed by high-resolution climate modelling. Geophys. Res. Lett., 36(12), L12501 (doi: 10.1029/ 2009GL038110)

Gogineni S, Chuah T, Allen C, Jezek K and Moore RK (1998) An improved coherent radar depth sounder. J. Glaciol., 44(148), 659-669

Gogineni S and 9 others (2001) Coherent radar ice thickness measurements over the Greenland ice sheet. J. Geophys. Res., 106(D24), 33 761-33 772 (doi: 10.1029/2001JD900183)

Hofton MA, Blair JB, Luthcke SB and Rabine DL (2008) Assessing the performance of $20-25 \mathrm{~m}$ footprint waveform lidar data collected in ICESat data corridors in Greenland. Geophys. Res. Lett., 35(24), L24501 (doi: 10.1029/2008GL035774)

Howat IM, Smith BE, Joughin I and Scambos TA (2008) Rates of southeast Greenland ice volume loss from combined ICESat and ASTER observations. Geophys. Res. Lett., 35(17), L17505 (doi: 10.1029/2008GL034496)

Humbert A and Steinhage D (2011) The evolution of the western rift area of the Fimbul Ice Shelf, Antarctica. Cryosphere, 5(4), 931-944 (doi: 10.5194/tcd-5-1089-2011)

Jezek KC (2003) Observing the Antarctic ice sheet using the RADARSAT-1 synthetic aperture radar. Polar Geogr., 27(3), 197-209 (doi: 10.1080/789610167)

Jezek KC (2008) The RADARSAT-1 Antarctic Mapping Project. (BPRC Report No. 22) Byrd Polar Research Center, Ohio State University, Columbus, $\mathrm{OH}$

Jezek K, Gogineni P, Wu X, Rodriguez E, Rodriguez F and Freeman A (2009) Global ice sheet mapping observatory: airborne experiments. In Proceedings of IEEE Conference on Radar (RadarCon09), 4-8 May 2009, Pasadena, CA. Institute of Electrical and Electronics Engineers, Piscataway, NJ, 1-4 
Jezek KC and 7 others (2011a) Two-frequency radar experiments for sounding glacier ice and mapping the topography of the glacier bed. IEEE Trans. Geosci. Remote Sens., 49(3), 920-929 (doi: 10.1109/TGRS.2010.2071387)

Jezek K and 6 others (2011b) Radar images of the bed of the Greenland Ice Sheet. Geophys. Res. Lett., 38(1), L01501 (doi: 10.1029/2010GL045519)

Joughin I, Smith BE, Howat IM, Scambos T and Moon T (2010) Greenland flow variability from ice-sheet-wide velocity mapping. J. Glaciol., 56(197), 415-430 (doi: 10.3189/ 002214310792447734)

Koenig L, Martin S, Studinger M and Sonntag J (2010) Polar airborne observations fill gap in satellite data. EOS, 91(38), 333-334 (doi: 10.1029/2010EO380002)

Krabill WB (2010) IceBridge ATM L1B Qfit elevation and return strength [updated 2013]. NASA Distributed Active Archive Center, National Snow and Ice Data Center, Boulder, CO. Digital media: http://nsidc.org/data/ilatm1b.html

Lei S and 8 others (2010) Multichannel coherent radar depth sounder for NASA Operation Ice Bridge. In Proceedings of International Geoscience and Remote Sensing Symposium (IGARSS), 25-30 July 2010, Honolulu, HI, USA. Institute of Electrical and Electronics Engineers, Piscataway, NJ, 1729-1732

Leuschen C and Allen C (2010) IceBridge MCoRDS L2 ice thickness. NASA Distributed Active Archive Center, National Snow and Ice Data Center, Boulder, CO. Digital media: http:// nsidc.org/data/irmcr2.html

Li J and 7 others (2013) High-altitude radar measurements of ice thickness over the Antarctic and Greenland ice sheets as a part of Operation IceBridge. IEEE Trans. Geosci. Remote Sens., 51(2), 742-754 (doi: 10.1109/TGRS.2012.2203822)

Munk J, Jezek KC, Forster RR and Gogineni SP (2003) An accumulation map for the Greenland dry-snow facies derived from spaceborne radar. J. Geophys. Res., 108(D9), 4280-4291 (doi: 10.1029/2002JD002481)
Paden J, Akins T, Dunson D, Allen C and Gogineni S (2010) Icesheet bed 3-D tomography. J. Glaciol., 56(195), 3-11 (doi: 10.3189/002214310791190811)

Peters LE, Anandakrishnan S, Holland CW, Horgan H, Blankenship DD and Voigt DE (2008) Seismic detection of a subglacial lake near the South Pole, Antarctica. Geophys. Res. Lett., 35(23), L23501 (doi: 10.1029/2008GL035704)

Peters ME, Blankenship DD, Carter SP, Kempf SD, Young DA and Holt JW (2007) Along-track focusing of airborne radar sounding data from West Antarctica for improving basal reflection analysis and layer detection. IEEE Trans. Geosci. Remote Sens., 45(9), 2725-2736 (doi: 10.1109/TGRS.2007.897416)

Rignot E, Mouginot J and Scheuchl B (2011) Ice flow of the Antarctic Ice Sheet. Science, 333(6048), 1427-1430 (doi: 10.1126/science.1208336)

Rodriguez-Morales $\mathrm{F}$ and 17 others (in press) Advanced multifrequency radar instrumentation for polar research. IEEE Trans. Geosci. Remote Sens. (doi: 10.1109/TGRS.2013.2266415)

Schutz BE, Zwally HJ, Shuman CA, Hancock D and DiMarzio JP (2005) Overview of the ICESat Mission. Geophys. Res. Lett., 32(21), L21S01 (doi: 10.1029/2005GL024009)

Sorge E (1933) The scientific results of the Wegener Expeditions to Greenland. Geogr. J., 80(4), 333-344

Van der Veen CJ (1999) Fundamentals of glacier dynamics. AA Balkema, Rotterdam

Waite AH Jr (1966) International experiments in glacier sounding, 1963 and 1964. Can. J. Earth Sci., 3(6), 887-892 (doi: 10.1139/ e66-071)

Waite AH and Schmidt SJ (1962) Gross errors in height indication from pulsed radar altimeters operating over thick ice or snow. Proc. Inst. Radio Eng., 50(6), 1515-1520 (doi: 10.1109/ JRPROC.1962.288195)

Wu X, Jezek KC, Rodriguez E, Gogineni S, Rodriguez-Morales F and Freeman A (2011) Ice sheet bed mapping with airborne SAR tomography. IEEE Trans. Geosci. Remote Sens., 49 (10 Pt 1), 3791-3802 (doi: 10.1109/TGRS.2011.2132802) 